\title{
Correction to: Rim lesions are demonstrated in early relapsing-remitting multiple sclerosis using 3 T-based susceptibility-weighted imaging in a multi-institutional setting
}

Koy Chong Ng Kee Kwong ${ }^{1}$ - Daisy Mollison ${ }^{1} \cdot$ Rozanna Meijboom ${ }^{1}$ • Elizabeth N. York ${ }^{1}$. Agniete Kampaite ${ }^{1}$. Sarah-Jane Martin ${ }^{2}$ - David P. J. Hunt ${ }^{1} \cdot$ Michael J. Thrippleton ${ }^{1}$. Siddharthan Chandran ${ }^{1} \cdot$ Adam D. Waldman $^{1}$ (1) . FutureMS consortium

Published online: 5 November 2021

(c) The Author(s) 2021

Correction to: Neuroradiology (2021)

https://doi.org/10.1007/s00234-021-02768-x

Originally, the first author's name has been erroneously published, with the surname appearing as Kwong instead of $\mathrm{Ng}$ Kee Kwong.

The original article has been corrected.

Publisher's note Springer Nature remains neutral with regard to jurisdictional claims in published maps and institutional affiliations.

The original article can be found online at https://doi.org/10.1007/ s00234-021-02768-x.

Adam D. Waldman

Adam.Waldman@ed.ac.uk

1 Centre for Clinical Brain Sciences, University of Edinburgh,

Edinburgh bioQuarter, Chancellor's Building, 49 Little

France Crescent, Edinburgh EH16 4SB, UK

2 Department of Neurosciences, University of Glasgow, Glasgow, UK 